\title{
Chaining biodiversity and neologism livability
}

\author{
Sengupta N and Bandyopadhyay J (eds). 2003 \\ Biodiversity and Quality of Life \\ New Delhi: Macmillan India Ltd
}

Reviewed by Anandajit Goswami

Resources, Energy, and Development 4(1): 89-96

The book edited by Nirmal Sengupta and Jayanta Bandyopadhyay comprising 20 chapters is a collation of selected papers of the Third Biennial Conference of the Indian Society for Ecological Economics; which was organized in Kolkata during December 2003 by the Centre for Development and Environment Policy of IIM (Indian Institute of Management), Kolkata. This concise volume provides a broad direction to ecological economists, academia, and researchers regarding the interface of ecology, environment, and development. The book deals with the 'quality of life', which was defined by Aristotle in an unique way. Aristotle gave much thought in his Nicomachean Ethics and eventually settled on the notion of eudemonia, a Greek term often translated as 'happiness', as being central to it. The neologism liveability from the adjective 'liv(e)able', is often applied to the built environment or a town or city, meaning its overall contribution to the quality of life of the inhabitants. The pertinent question is whether one can define the quality of life with regard to its linkage with biodiversity in the same way as neologism liveability.

The book gives an overview and the methodological details and modelling techniques associated with the wide-ranging issue of biodiversity and its impact on the quality of life by focusing on the definition of the human economy as a 'small open subsystem embedded in large social, ecological system'. This entails economic accounting of the inflows and outflows of energy and materials in and out of the economy, which affect the quality of life. The book first gives an overview through chapters dealing with current trends in critical areas of biodiversity, tools, and methodologies, followed by methodological issues, including chapters dealing with areas of valuation, economic impacts of human induced degradation, valuation of urban and peri urban ponds, followed by model building, which covers modelling approaches of optimization and game-theoretic tools.

Chapter 1, Conservation and the future: trends and options towards the year 2025 by Jeffrey A McNeely, starts with the Club of Rome Report, which dwells on the possible collapse of the world economic system due to population growth and resource consumption. It emphasizes the neo-Malthusian view of growth in population being responsible for the growth in consumption, along with suggesting ways of checking the situation through rapid technological growth. The chapter discusses the chaotic behaviour of various species that significantly impacts the balanced growth of resources and population. Thereby, it deals 
with the changes in population; consumption of resources; cultural diversity brought about by the spread of knowledge through new information technology and an enhanced understanding of the different cultural, environmental, economic, linguistic, and institutional realities; and the linkage of India's development in biodiversity conservation with international programmes like the WTO (World Trade Organization).

Chapter 2, Role of ecosystems in sustainable development by Mohan Munasinghe and Walter Reid, and Chapter 3 on the Economics of environment: lessons from ecology by Charles Perrings define sustainable development as encompassing the dimensions of economic (growth, efficiency, and stability), social (empowerment, inclusion, and governance), and environmental (resilience/biodiversity, natural resources, and pollution) indicators. The linkage between economic and social indicators is established through intragenerational equity and basic needs/ livelihoods, and that between social and environmental indicators is established through intergenerational equity, values, and culture. These two chapters establish the linkage between sustainable development and the ecosystem through three layers, viz. global, regional, and local, and highlight the contribution of the science of ecology towards the quality of life by assessing its impact on the integration of ecology and economics and how it has effected environmental management and policy-making. These chapters explore the conceptual frameworks, analytical tools, and indicators that help to incorporate biodiversity and ecosystem considerations for policy analysis and implementation by focusing on the following.

- Human well being and poverty reduction (material minimum for good health, freedom, and choice)

- Ecosystem services (provision of goods, water, cultural and spiritual services and aesthetic supporting services like primary health)
- Indirect drivers of change (demographic transition, globalization, and trade)

- Direct drivers of change (change in local land use and cover, introduction of new species, and adaptation of new technologies)

- Dynamics of hierarchial ecological systems that offer new ways of economic development and change

- Substitutability of produced and natural capital

- Resilience of ecological systems towards the stability and sustainability of economic states

- Linkage between biodiversity and ecosystem function

- Frameworks for managing ecosystems and ecosystem services for making development more sustainable at the national level

Chapter 3 uses a random utility model to estimate the net benefits of a trip to the park and a marginal willingness to pay is found for the visitors to the park. A contingent valuation approach is also used to find out the environmental and social impacts along with a multicriteria approach in estimating the economic indicator, biodiversity index, number of resettled people, etc. where each major objective is represented by one variable assuming all other attributes to be minor, which might not be true in reality.

With regard to the dynamics of hierarchial process, Chapter 3 reviews the insight given by Norgaard (1988). The dynamics of the social system is analysed through the 'butterfly effect' that demonstrates how localized shortterm decisions affect the dynamics of small fast-moving systems. This could finally impact large slow-moving systems through epidemic behaviour and dependence on the coupled dynamics of temporal interactions between different systems. The chapter highlights the environmental limits of growth, mentioning the environmental assimilative capacity and the speed with which an environmental system comes back to equilibrium through the shallow 
lake models of Carpenter, Brocks, and Hansen. These models show how market and policy disturbances could induce a change in biodiversity by affecting the levels of fertilizer applications. Hence, the chapter gives a functional relationship between the market elements and the consumption bundle through the effect of the market in the preference pattern of the environmental resources after accounting for the impact of people's actions, and preference pattern on biodiversity and the quality of life.

Chapter 4 on Economics of indigenous, traditional knowledge by Nirmal Sengupta, and Chapter 5 on Weaknesses of existing datasets on mountain ecosystems-evidences from natural terrestrial ecosystems in the Himalaya by Ranbeer S Rawal, Upendra Dhar, and Sumit Manjkhola, underscore the importance of traditional knowledge in biodiversity conservation. Article 8 of the CBD (Convention on Biological Diversity) takes up the customary use of biological resources; exchange of information on indigenous and traditional knowledge; development in the methods of co-operation for use; and an assessment of the importance of a database for the mountain ecosystems, conservation of the ecosystem for ascribing ecological, economic values to the ecosystem through the assessment of representativeness, uniqueness, sensitivity, and biological integrity in the existing database. Chapter 4 defines local knowledge as the knowledge, innovation, and practices of indigenous and local communities, which embody their traditional lifestyle. It emphasizes the value of such traditional knowledge by giving an estimate of the market value of plant-based medicines sold in OECD (Organization for Economic Cooperation and Development) countries. There is the necessity of the trickling down of the benefits of traditional knowledge to the people whose knowledge is being used in generating these products, which are then marketed, to generate profits. The paper supports this by bringing up the case of how $80 \%$ of the database references of the US Patent Office were on seven medicinal plants of Indian origin. The importance of biodiversity and sharing of its benefits is emphasized in this chapter in the light of the references to the CBD, bio-prospecting, IPR (Intellectual property rights), the Patent Act (1970), the Protection of Plant Varieties and Farmers Rights Act (2001), and the WIPO (World Intellectual Property Organization). The following methods of benefit sharing are suggested: (1) asking patent applicants to disclose the origin of genetic resources, and the associated traditional knowledge; (2) improvement in the availability of the public domain traditional knowledge to patent examiners; (3) use of natural elements (such as the usage of natural dye instead of azo dye to maintain the environmental standards of leather products); (4) Protection of farmer's knowledge and agro biodiversity, and an assessment of the adaptable nature of the local people, which changes with the change in climate, and which has an impact on the biodiversity and on the quality of life. Chapter 5 focuses on the need to review the ecological database from the perspective of conservation and sustainable utilization of the species as well as their adaptability to changing environmental conditions.

Chapter 6, A national plan process, built from below: national biodiversity strategy and action plan, India by Ashish Kothari and Kanchi Kohli, gives the background to India's commitment in it being a part of the CBD. It also explains how the National Biodiversity Strategy and Action Plan has evolved over the years after the Government of India applied to the GEF (Global Environment Facility) through the UNDP (United Nations Development Programme) for a comprehensive strategy action plan by the MoEF (Ministry of Environment and Forests) to implement it. The chapter highlights the role of mass media, folk media, traditional communication methods, and public hearing methods. These have actively contributed to 
the policy dissemination and hindrance faced by the programme due to bureaucratic inefficiency, lack of women's involvement, and delays at the MoEF level in many states, despite of its implementation in states like Karnataka, Assam, Andhra Pradesh, Rajasthan, Madhya Pradesh, Nagaland, Sikkim, Punjab, and Haryana.

The second section of the book deals with the methodological facets. It starts with Chapter 7 , Linking biodiversity with quality of life: issues of assessment, resilience and model integration by Gopal K Kadekodi. The chapter links the biodiversity concerns with quality of life through a biophysical approach, by using an economic approach (through a monetary valuation) to integrate the economic system with the ecosystem. The importance of the resilience of an ecosystem for a mutually supportive integration between economics and ecology is highlighted with an emphasis on the asymmetric nature of information on the socio-economic aspects of the resilience. The chapter brings out the fact that the larger interconnection between a system could contribute to its degree of instability.

Chapter 8 by Jeena T Srinivasan on the Economic impact of ecosystem degradation and options for sustainable resource management addresses the economic impact of the human-induced degradation of the Cochin Estuary in Kerala and analyses the estuary-fishery linkage through primary and secondary sources, and through econometric tools like OLS (ordinary least squares) and logit models with a production function approach. The results conclude that heterogeneity in terms of endowments and technology favours participation and often create opposition if people think that they might loose resources through a collective decision that could create new property rights definition, thus creating a loss in the access to property rights of natural resources by one set of people.

Chapter 9 by Siddhartha Majumdar, and Mohit Kumar Ray on Evaluating economic sustainability of urban and peri-urban water bodies: a case study from Kolkata ponds underscores the importance of water resource quality management in urban, and peri-urban areas which are facing the pressures of the growing population and the multifaceted use of city ponds for bathing, washing, pisciculture, religious rites, and its use in city parks. The results of the study show that

- value contributed by a pond is significant as urban, peri-urban ponds are the main sources of water for a large number of people, and

- sustainability and mutual compatibility of human use of ponds and pisciculture can be attained through community management.

Chapter 10, on Loktak Lake: its biodiversity and lake people by Ksh Jhaljit Singh focuses on Loktak Lake, taking into account the multifaceted economic, and cultural aspects as various anthropocentric activities have resulted siltation, weed infestation, decrease in fisheries production, flooding, and pollution. The chapter discusses the ICEF (International Council for Environmental Fund) project under which 'catchment area development', 'water body treatment', control of soil erosion, 'water management', 'optimization of lake level', and 'enhancement of water holding capacity' have taken place. This project has finally led to community participation and the development of biodiversity sources like Loktak Lake.

Chapter 11 Causes of fish depletion: a factor analysis approach by T K Deka, M M Goswami, and M M Kakati, is based on a study conducted in 54 wetlands of 13 districts of Assam for evaluating the causes of fish depletion in the wetlands. Twenty-two variables under seven factors (management deficiency, organic load interference, catchment condition, extrinsic influence, fisherman's ignorance, external environment, and aquaculture programme), are considered, and a principal component analysis is carried out based on the Eigen value criteria of more 
than one. One of the interesting results of the model is that all wetlands registered fish depletion of varying degrees, and that the management deficiency (Factor 1) and aquaculture programme (Factor 6) were the most significant factors.

Chapter 12 on Sustainable livelihoods and resource management strategies in Kenya: the role of seasonal migration and non-farm activities by Jane Kabubo Mariara analyses two aspects of sustainable livelihoodsmigration with livestock and non-farm activities following the sustainable livelihood approach. The analysis explores labour allocation decisions by herders, as well as the choice of optimal distance migrated once a herder decides to migrate. The study focuses on non-farm activities and the resulting incomes as a means of diversifying livelihoods in the face of environmental risks. The Herckman selection model is used to control the selectivity bias in the migration decision and the distance migration process, participation in non-farm activities, and the income derived from such activities. The model is based on simplifying assumptions embodying factors influencing the number of hours worked in non-farm activities, profit generation, and exogenous factors. Optimal labour input is achieved by the principal of equalization of the marginal revenue product of labour to the market wage rate, followed by probit modelling to determine the impact of factors influencing household behaviour with respect to migration and participation in nonfarm activities. The model indicates that the scarcity of water and the division in which a household is located has a positive impact on labour allocation for distance migration. The results indicate that the level of education, livestock ownership, total available labour, property rights, remittances, and regional dummies positively influence commutation with livestock with a difference between daily and long-distance commutation with livestocks. The model indicates that households with more land migrate for shorter distances and that mobile pastoral systems are more sustainable than sedentary systems allowing regeneration of biomass and increasing productivity of herds during droughts.

Chapter 13 on Organic farming in north east hill region in India by Nilabja Ghosh deals with the research question of whether organic farming is exclusive to a particular group, or crop, or is practiced along with other chemical inputs in the north-eastern hilly states of India. The chapter applies a multinomial logit model to understand the decisions of the farmers with regard to the choice of organic and other fertilizer usages, and indicates that traditional practices are used to a greater extent in the case of pulses and mixed crop groups other than the base crop groups including wheat and rice, which have a higher fertilizer usage.

Chapter 14, Ecological and economic aspects of biodiversity conservation in a protected area, India by Jyothis Sathyapalan and $\mathrm{K}$ N Ninan, discusses the research question of whether use rights out of conventional arrangements are important in the degradation of protected areas. This is achieved through a choice contingent survey of the pilgrims' stated willingness to pay, to avoid the loss of biodiversity in the pilgrimage. The logit model used for the study estimates an expected willingness to pay an amount of 28.70 rupees per respondent for biodiversity conservation by using significant variables like bid amount, income, environmental attitude score, age of pilgrim, and number of visits made to reserve, and shows that people exercising defacto access rights have a positive attitude for mitigation of environmental degradation, which, thereby, raises the policy need for protection of such defacto access rights for biodiversity conservation.

The third section of the book on models starts with Chapter 15 on Forest biodiversity and timber extraction: an analysis of the interaction of market and non-market mechanisms by Kanchan Chopra and Pushpam Kumar. The chapter deals with the research 
question of the implications of institutional regimes on the extraction of products and services, and policies like plantations that are intended to increase the supply of marketed product like timber, and bring about a change in the biodiversity of forest stock, which creates a decreased availability of nonmarketed products. The chapter presents a model using a biodiversity index (defined as a product biodiversity index), and a variable depicting the ecological characteristics of the forests using a modified Gordon-Schaefer' production function with the assumption that forests are managed for 'sustainable timber extraction'. The model indicates that in the absence of variables like plantation area and biodiversity corrected stocks, the model has a low explanatory power, although extraction is significantly affected by effort. An increase in biodiversity could imply a decreasing trend in extraction in the future if the present extraction rate does not increase at a faster rate than the rate of increase in biodiversity.

Chapter 16, Dynamics of the resource economic of open access grassland-Kutch District, by C P Geevan, Arun M Dixit, and C S Silori, deals with a dynamic simulation model to explain the dynamics of the ecological and economic linkages of open access of grasslands, livestock, and its invasion by woody cover to deal with the woody invasion of grasslands causing a loss in their biodiversity values. The primary data shows that most people prefer regeneration of grassland resources, although the revenue projections of the model do not account for the importance of the livestock as an asset. The simulations of the dynamic model computes income from wood charcoal, assuming that the pastoral community is also the producer of wood charcoal, which may not be reasonable for the scale of production used in the simulation. In reality, with such a scale of production, only a small section of the pastoral community would stand to gain, while most of the herders would turn to seasonal labour. This model thus brings out the need for providing economic returns to the pastoral community, which could be achieved feasibly by a joint management regime through a partnership of the forest department and the herders.

Chapter 17, Sustainable management of Chilka Prawan Fisheries by A K Choudhury, N C Sahu, and Charles Perrings pertains to a decline in the shrimp catch through deterioration in environmental condition, and an open access regime. The modified GordonSchaefer model proposed by Schnute is used to indicate three outcomes-maximum sustainable yield, open access, and profit maximization and indicates the exploitation level of fisheries and its regulation. The model brings in the stochastic element and environmental factors like sedimentation and falling salinity, unlike the traditional GordenSchaefer model to explain the productivity of prawn fisheries of Lake Chilka. The corresponding regression analysis shows that environmental factors like salinity significantly determine the intrinsic growth rate of prawn fishery resources.

Chapter 18, Mangrove fishery linkages under alternative policy regimes, by Kaushik Gupta, determines the optimal conservation rate of mangroves and fisheries for community profit maximization using a Hamiltonian framework with the assumption that the community authority aims to achieve its objective of conservation by imposing a tax on forest resources, thus affecting the cost of mangrove harvest. Two alternative policy regimes of conservation and taxation are considered to achieve the objective of community profit maximization. However, on comparing the results of the conservation regimes with the tax regime, it was found that the conservation regime was more acceptable than taxation from the perspective of a community. Further, the policy regime of maximum allowable harvest level was considered, and it was found that in order to compensate for the loss of forestry profit through the conservation of forests the 
community, authorities must give incentives to the fishery sector to raise their profits thereby improving the level of joint profit.

Chapter 19, Coastal mangrove ecosystems, fisherman's welfare and anthropogenic externalities: compensatory payments through mangrove-fishery linkages, by Nilanjan Ghosh and C S Shylajan, focuses on the rule of compensatory payment for the fishing community depending on the fishery products, which mature with the provision of mangrove as a habitat. The chapter elucidates how emissions in the upstream affect the natural habitation, creating an economic loss for the fishermen by damaging the fishing species dwelling in mangrove habitats. The chapter illustrates that compensatory payment by using a Lagrangian function with the maximization of the upstream profit of the producer of the product, and the downstream profit of the fisherman (using a Schaefer production function), with the constraint of minimum amount of ecologically defined mangrove vegetation and water requirement for the economic and ecological sustenance of downstream segment, and generation of product by upstream producers for their sustenance. The shadow values of the model become the basis for compensation and the movement of shadow values contributes in framing policy decisions to address the compensation to be provided to the fishermen. One important finding of the chapter is the 'scarcity value' of environmental services; that is, the value lost and realized by the society due to its scarcity, which could be linked to the 'effluent-emitting industries impacting the downstream mangrove forests of Sundarbans' in the 'Ganges sub-basin in India'.

Chapter 20, by Lekha Mukhopadhyay, analyses the effect of inequality in the distribution of private wealth that are complementary inputs in production, along with some collective inputs extracted from common property resources, specifically in the context of a situation where access to technologies for the extraction of CPR (community property rights) is determined by distribution of wealth. The chapter considers a 'Nash bargaining' solution for a two-stage bargaining model, and there is a move from a non-cooperative to a cooperative outcome, showing that in a society with inequality in terms of access to land and technology for resource extraction, negotiation towards a cooperative outcome increases with an increasing inequity in the distribution of the payoffs from the common property resources. This indicates that a policy-maker could design an incentive scheme for conservation of common property resources with lack of uniformity in the incentive prices for conservation.

The strength of the book lies in its comprehensive overview and methodological and modelling details, covering various features of the linkage between biodiversity and the quality of life. Although the preface aptly mentions the issue of equitable benefit of biological resources across local, national, and global societies, the book leaves some scope for greater analysis regarding Article 27.2 of TRIPS (Trade Related Aspects of Intellectual and Property Rights), Article 16 of the CBD, and Nature of submissions in the WTO in the area of trade, environment, and biodiversity linkage. This would provide future directions to research in the area of how global legislative, institutional, regulatory, and trade regimes affect biodiversity and the quality of life across the different blocks of countries, viz. developed, developing, and least developed.

These papers reveal that the issue of the linkage between biodiversity and the quality of life deals with the evolution of society, and it perceptions and beliefs. In this regard, it is important to include the various facets linked to the quality of life, comprising ecological, scientific, geological, geographical, scientific, and anthropological dimensions. This amalgamation can be achieved only through wider transdisciplinary socially responsible research involving the scientific community 
from all fields. There has to be a wider proactive engagement between science, citizens, and the society. This is also reflected in Science and Citizens: Globalization and the challenge of engagement by Melissa Leach, Ian Scoones, and Brian Wynne (2005). In the current scenario of globalization, the authors have focussed on the importance of responsible research in forging a connection between science and society that would have an impact on the pattern and quality of life of the citizens. This is typically applicable to the field of biodiversity in which the there is an emergence of a growing need for transdisciplinary research among its various streams in order to impact the society positively by enhancing the quality of life of the people. This book substantiates the need to bring in transdisciplinary thinking in the streams of research in biodiversity by bridging the gap between the science of biodiversity and the citizens of a society so as to enable sustainable development.

\section{References}

Norgard R B. 1988

Gaining citizenship: rights, participation, accountability

in Biodiversity, edited by Wilson $\mathrm{E} \mathrm{O}$ and

Frances P M

Washington DC: National Academics Press

Leach M, Scoones I, and Wyne B. 2005

Science and Citizens: Globalization and the challenge of engagement

London: Zed Books 